\title{
Mechanical force promotes the proliferation and extracellular matrix synthesis of human gingival fibroblasts cultured on 3D PLGA scaffolds via TGF- $\beta$ expression
}

\author{
LAN NAN, YI ZHENG, NI LIAO, SONGZE LI, YAO WANG, ZHIXING CHEN, \\ LIYING WEI, SHUANG ZHAO and SHUIXUE MO \\ Department of Stomatology, Guangxi Medical University, Nanning, Guangxi 530021, P.R. China
}

Received January 27, 2018; Accepted December 6, 2018

DOI: $10.3892 / \mathrm{mmr} .2019 .9882$

\begin{abstract}
Human gingival fibroblasts (HGFs) are responsible for connective tissue repair and scarring, and are exposed to mechanical forces under physiological and pathological conditions. The exact mechanisms underlying gingival tissue reconstruction under mechanical forces remain unclear. The present study aimfed to investigate the effects of mechanical forces on the proliferation and extracellular matrix synthesis in HGFs by establishing a 3-dimensional (3D) HGF culture model using poly(lactide-co-glycolide) (PLGA) scaffolds. HGFs were cultured in 3D PLGA scaffolds and a mechanical force of $0,5,15,25$ or $35 \mathrm{~g} / \mathrm{cm}^{2}$ was applied to HGFs for $24 \mathrm{~h}$. A mechanical force of $25 \mathrm{~g} / \mathrm{cm}^{2}$ induced the highest proliferation rate, and thus was selected for subsequent experiments. Cell viability was determined using the MTT assay at $0,24,48$ and $72 \mathrm{~h}$. The expression levels of type I collagen (COL-1) and matrix metallopeptidase (MMP)-1 were examined by reverse transcription-quantitative polymerase chain reaction and ELISA, and transforming growth factor (TGF)- $\beta$ expression was evaluated by ELISA. The application of mechanical force on HGFs cultured on the 3D PLGA scaffolds resulted in a significant increase in cell proliferation and COL-1 expression, as well as a decrease in MMP-1 expression. A TGF- $\beta 1$ inhibitor was also applied, which attenuated the effects of mechanical force on HGF proliferation, and COL-1 and MMP-1 expression, thus suggesting that TGF- $\beta$ signaling
\end{abstract}

Correspondence to: Dr Shuixue Mo, Department of Stomatology, Guangxi Medical University, 10 Shuangyong Road, Nanning, Guangxi 530021, P.R. China

E-mail: xsnanlan.98@qq.com

Abbreviations: ECM, extracellular matrix; HGFs, human gingival fibroblasts; MMP-1, matrix metallopeptidase 1; OD, optical density; PGA, polyglycolic acid; PLA, polylactic acid; PLGA, poly(lactide-co-glycolide); RT-qPCR, reverse transcription-quantitative polymerase chain reaction; TGF- $\beta$, transforming growth factor- $\beta$

Key words: mechanical force, human gingival fibroblasts, 3D culture, PLGA, TGF- $\beta$ pathways may mediate the mechanical force-induced alterations observed in HGFs. In conclusion, these findings helped to clarify the mechanisms underlying mechanical force-induced HGF proliferation and ECM synthesis, which may promote the development of targeted therapeutics to treat various diseases, including gingival atrophy caused by orthodontic treatment.

\section{Introduction}

Orthodontic treatment alters the location of abnormally positioned teeth by applying mechanical force, which in turn affects the attachment apparatus, including the periodontal ligament, alveolar bone, cementum and gingiva (1). Tooth movement is achieved following alveolar bone remodeling and response of the periodontal ligament to mechanical force (2). In recent decades, alveolar bone and periodontal membrane remodeling under mechanical force have been widely studied (3). However, the mechanisms underlying gingival tissue reconstruction remain largely unexplored.

Gingival tissues are constantly exposed to the effect of physical forces (4). Mechanical stimuli are regulators of connective tissue homeostasis, and sustained mechanical stimulation may lead to modifications in cell activity and extracellular matrix (ECM) composition (5). Human gingival fibroblasts (HGFs) are the major cell type that constitutes human gingival connective tissue (6), which are responsible for the synthesis and degradation of the ECM and bone resorption, as well as the secretion of proteolytic enzymes (7-9). Accordingly, they are crucial for regulating the homeostasis of periodontal tissues under healthy and diseased states (10). Nevertheless, strategies to improve correction efficiency and promote HGFs to maintain the stability of adaptive remodeling following orthodontic treatment remain to be elucidated.

Transforming growth factor (TGF)- $\beta$ is an important regulator of gingival tissue regeneration (11-13). Guo et al (14) demonstrated that mechanical shear force promotes the proliferation of gingival fibroblasts through activation of the TGF- $\beta$ signaling pathway. In addition, Jeon et al (15) revealed that mechanical force induces the synthesis of type I collagen (COL-1) and osteopontin in HGFs through TGF- $\beta$ signaling. Therefore, it was hypothesized that TGF- $\beta$ may have an important role in converting mechanical force into 
biochemical signals in HGFs, thus promoting cell proliferation and extracellular ECM synthesis.

Since other cells and ECM surround almost all cells in the in vivo environment in a 3-dimensional (3D) fashion, 2-dimensional (2D) cell culture does not adequately take into account the natural 3D environment of cells (16). The development of biological scaffold material provides a structural basis for 3D cell culture (17). Cells cultured in a 3D cell-based system more realistically mimic in vivo cell behaviors and provide more predictable results for subsequent in vivo experiments. Biodegradable poly(lactide-co-glycolide) (PLGA) is a biocompatible material that is widely used in clinical settings (18). In the present study, a 3D HGFs culture model was established, using PLGA scaffolds, in order to investigate the effects of mechanical force on the proliferation of HGFs, and to explore the functions of TGF- $\beta$ in HGF proliferation, as well as COL-1 and matrix metallopeptidase (MMP)-1 expression. The results may provide a theoretical basis for the understanding of gingival remodeling under mechanical force.

\section{Materials and methods}

$3 D$ culture of HGFs. HGFs were 3D cultured as previously reported (19). Gingival tissues were collected from healthy teeth extracted from 17 males and 19 females (age range, 10-14 years) during orthodontic extraction or gingival resection. Subsequently, the tissues were dissociated using $0.25 \%$ trypsin (Sigma-Aldrich; Merck KGaA, Darmstadt, Germany) containing 100 ng/ml DNase (Roche Diagnostics, Basel, Switzerland) at $37^{\circ} \mathrm{C}$ for $35 \mathrm{~min}$. The digestion was terminated by adding Dulbecco's modified Eagle's medium (GE Healthcare Life Sciences, Logan, UT, USA) with $10 \%$ fetal bovine serum (Gibco; Thermo Fisher Scientific, Inc., Waltham, MA, USA). The dissociated HGFs were cultured in Eagle's minimum essential medium (Invitrogen; Thermo Fisher Scientific, Inc.) supplemented with $10 \%$ fetal bovine serum (Gibco; Thermo Fisher Scientific, Inc.), 2 mM L-glutamine and $100 \mathrm{U} / \mathrm{ml}$ antibiotics (Gibco; Thermo Fisher Scientific, Inc.) in plastic culture flasks. Cells were maintained at $37^{\circ} \mathrm{C}$ with $5 \% \mathrm{CO}_{2}$. The PLGA scaffold (size, $2 \mathrm{~cm}$ x $2 \mathrm{~cm} \times 300 \mu \mathrm{m}$; porosity, $85 \%$; average pore size, $80-120 \mu \mathrm{m}$ ) was synthesized using the solvent casting/particulate leaching technique (20). After 4-6 passages, $1 \times 10^{5}$ HGFs were seeded onto a single sheet of PLGA scaffold. The present study was approved by the Hospital Institutional Review Board (approval no. 20150304-22) of Guangxi Medical University (Nanning, China). All donors and their guardians signed an informed consent form.

Application of mechanical force. Prior to the application of mechanical force, HGFs were allowed to stabilize for $48 \mathrm{~h}$. HGFs were continuously compressed using the uniform compression method, as presented in Fig. 1. Briefly, the PLGA sheet was placed into the well with a wire stool to prevent it from floating. A HGF suspension was dripped into the well. After $24 \mathrm{~h}$ of incubation at $37^{\circ} \mathrm{C}$, the PLGA/HGF construct was moved to another well. After cell implantation for $6 \mathrm{~h}$, glass bottles containing lead granules were placed on top of the 3D models. The bottles provided compressive stress of four magnitudes $\left(5,15,25\right.$ and $\left.35 \mathrm{~g} / \mathrm{cm}^{2}\right)$ for 6,24 and $72 \mathrm{~h}$. Control cells (without application of mechanical force) were cultured under the same 3D conditions. Cells were also cultured at $37^{\circ} \mathrm{C}$ in the presence of SB431542 (cat. no. HY-10431; MedChemExpress Monmouth Junction, NJ, USA) for $24 \mathrm{~h}$, a TGF- $\beta$ inhibitor, at $20 \mu \mathrm{M}$.

Immunocytochemistry. HGFs from the PLGA scaffold were plated on coverslips and incubated for $6 \mathrm{~h}$ at $37^{\circ} \mathrm{C}$ in an atmosphere containing $5 \% \mathrm{CO}_{2}$, in order to allow cells to adhere and proliferate. Cells were harvested and fixed with $4 \%$ paraformaldehyde for $30 \mathrm{~min}$ at room temperature. Peroxidase activity was blocked using $3 \%$ hydrogen peroxide for $30 \mathrm{~min}$ at $37^{\circ} \mathrm{C}$. After blocking in normal rabbit serum (Santa Cruz Biotechnology, Inc., Dallas, TX, USA), the cells were incubated with monoclonal antibodies against vimentin (cat. no. MAB3404; 1:100) and cytokeratin (cat. no. MAB3400; 1:100) (both from Sigma-Aldrich; Merck KGaA) at $4^{\circ} \mathrm{C}$ overnight. Following three washes with PBS for $5 \mathrm{~min}$ at room temperature, sheep anti-rat immunoglobulin G secondary antibody (1:5,000; cat. no. 5647; Abcam, Cambridge, UK) was added and incubated at $37^{\circ} \mathrm{C}$ for $1 \mathrm{~h}$. Subsequently, the membrane was analyzed using the UltraSensitive ${ }^{\mathrm{TM}}$ S-P Immunohistochemistry kit (cat. no. 40398a; Fuzhou Maixin Biotech. Co., Ltd., Fuzhou, China) according to the manufacturer's protocol. Finally, cells were counterstained with $3 \%$ hematoxylin for $60 \mathrm{sec}$ at room temperature and examined using a fluorescence microscope (Olympus Corporation, Tokyo, Japan).

Immunofluorescence. Sections of the scaffolds (300 $\mu$ m-thick) containing the HGFs were deparaffinized with xylene. Following rehydration with descending ethanol series, the samples were incubated for antigen retrieval in a microwave oven with EDTA buffer at $\mathrm{pH} 8.0$ for $30 \mathrm{~min}$ at $95^{\circ} \mathrm{C}$, followed by fixation with $4 \%$ paraformaldehyde for $30 \mathrm{~min}$ at room temperature. Immunofluorescence analysis was performed to detect fibrillar actin (F-actin) and nuclei. Structures of F-actin were detected using tetramethylrhodamine-phalloidin (Beijing Solarbio Science \& Technology Co., Ltd., Beijing, China) staining solution at a concentration of $100 \mathrm{nM}$ and incubated for $30 \mathrm{~min}$ at room temperature. Nuclei were stained with DAPI at $10 \mu \mathrm{g} / \mathrm{ml}$ for $30 \mathrm{sec}$ at room temperature (Sigma-Aldrich; Merck KGaA), according to the manufacturer's protocol. After washing with PBS, samples were examined by confocal microscopy (fv-500; Olympus Corporation).

Cell viability. Following the application of mechanical force, HGFs-PLGA constructs were incubated with MTT reagent (Sigma-Aldrich; Merck KGaA) for $4 \mathrm{~h}$ at $37^{\circ} \mathrm{C}$, at a concentration of $20 \mu \mathrm{M}$. Subsequently, $500 \mu \mathrm{l}$ DMSO (Sigma-Aldrich; Merck KGaA) was added into each well to dissolve the formazan and the optical density (OD) values were determined at $570 \mathrm{~nm}$.

Flow cytometry. Trypsin was used to detach and collect the cells from the PLGA scaffold, and cells were washed twice with PBS at $4^{\circ} \mathrm{C}$. The cells were collected by centrifugation at $300 \mathrm{x} \mathrm{g}$ for $5 \mathrm{~min}$ and were fixed in $1 \mathrm{ml}$ cold $70 \%$ ethanol for $30 \mathrm{~min}$ at $4^{\circ} \mathrm{C}$. Cells were resuspended in $1 \mathrm{ml}$ propidium iodide staining solution (cat. no. CCS012; Multisciences Lianke Biotech Co., Ltd., Hangzhou, China) and incubated for $30 \mathrm{~min}$ at room temperature. The stained cells were analyzed 


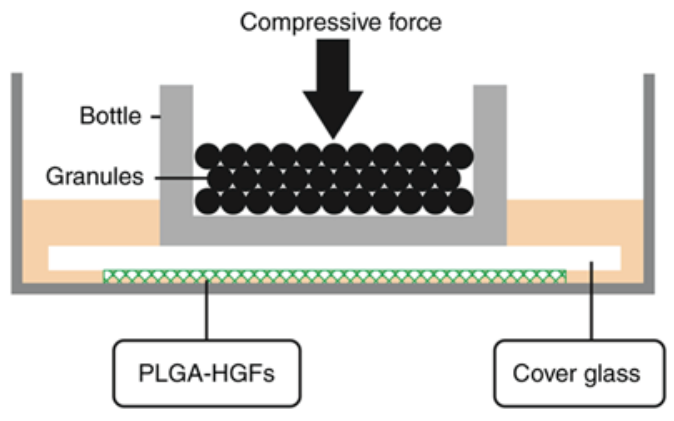

Figure 1. Schematic diagram of the uniform compression method of mechanical force loading. PLGA-HGFs, poly(lactide-co-glycolide)-human gingival fibroblasts.

for DNA content by flow cytometry (BD Accuri ${ }^{\mathrm{TM}}$ C6; BD Biosciences, Franklin Lakes, NJ, USA). The number of cells in the $S$ and $G 2 / M$ phases was divided by the number of cells in the G0/G1 phase, in order to calculate the proliferation index (ModFit LT software; version 4.0; Verity Software House, Inc., Topsham, ME, USA).

Reverse transcription-quantitative polymerase chain reaction $(R T-q P C R)$. Total RNA was isolated from HGFs on the PLGA scaffold using TRIzol ${ }^{\circledR}$ reagent (Invitrogen; Thermo Fisher Scientific, Inc.), according to the manufacturer's protocol. An additional round of purification was performed with deoxyribonuclease I (ribonuclease-free; Takara Bio, Inc., Otsu, Japan) to remove genomic DNA. RNA quality was assessed using RNA 6000 Nano-Chips on an Agilent 2100 Bioanalyzer (Agilent Technologies, Inc., Santa Clara, CA, USA). All samples showed intact $18 \mathrm{~S} / 28 \mathrm{~S}$ bands. Total RNA $(1 \mu \mathrm{g})$ underwent cDNA synthesis using an ExScript RT reagent kit (Takara Bio, Inc.), according to the manufacturer's protocol. RT-qPCR was performed using a T100 ${ }^{\mathrm{TM}}$ Thermal Cycler system (Bio-Rad Laboratories, Inc., Hercules, CA, USA), according to the manufacturer's protocol. The following primers were used: TGF- $\beta 1$, forward, 5'-CGCATCCTAGACCCTTTCTCCTC-3' and reverse, 5'-GGTGTCTCAGTATCCCACGGAAAT-3'; COL-1, forward, 5'-GAGGGCAACAGCAGGTTCACTTA-3' and reverse, 5'-TCAGCACCACCGATGTCCA-3'; MMP-1, forward, 5'-ACA ACTGCCAAATGGGCT TGA-3' and reverse, 5'-CTGTCCCTGAACAGCCCAGTACTTA-3'; and GAPDH, forward, 5'-GCACCGTCAAGGCTGAGAAC-3' and reverse, 5'-TGGTGAAGACGCCAGTGGA-3'. The RT-qPCR reactions were performed on an ABI 7300 Real-Time PCR system (Applied Biosystems; Thermo Fisher Scientific, Inc.) with SYBR Premix Ex Taq (Takara Biotechnology Co., Ltd., Dalian, China) at $95^{\circ} \mathrm{C}$ for $30 \mathrm{sec}$, followed by 40 cycles at $95^{\circ} \mathrm{C}$ for $5 \mathrm{sec}$ and $60^{\circ} \mathrm{C}$ for $31 \mathrm{sec}$, after which a melt curve analysis was performed at $95^{\circ} \mathrm{C}$ for $15 \mathrm{sec}, 60^{\circ} \mathrm{C}$ for $1 \mathrm{~min}$ and $95^{\circ} \mathrm{C}$ for $15 \mathrm{sec}$. All reactions were performed in triplicate and average of $2^{-\Delta \Delta \mathrm{Ct}}(21)$. GAPDH was used as an internal control. Each experiment was repeated at least three times.

ELISA. ELISA kits were used to quantify TGF- $\beta 1$ (cat. no. JL10706), COL-1 (cat. no. CSB-E08082h) and MMP-1 (cat. no. CSB-E08082h) levels (Quantikine; R\&D Systems, Inc., Minneapolis, MI, USA) according to the manufacturer's protocol. A standard curve was created with the serially diluted
TGF- $\beta 1$ standard provided in the kit. Samples were measured at $450 \mathrm{~nm}$ using a microplate reader (Model 3550; Thermo Fisher Scientific, Inc.). Data were linearized by plotting the log of the TGF- $\beta 1$ concentrations vs. the log of the OD; TGF- $\beta 1$ concentrations were determined by linear regression. COL-1 and MMP-1 protein levels were detected using the same method. Each sample was assessed in triplicate.

Statistical analysis. All data are presented as the means \pm standard deviation of three independent experiments. One-way analysis of variance (ANOVA) with Dunnett's post hoc test or two-way ANOVA with Bonferroni post hoc test was used for multiple comparisons. Statistical analyses were performed using SPSS 21.0 (IBM Corp., Armonk, NY, USA). $\mathrm{P}<0.05$ was considered to indicate a statistically significant difference.

\section{Results}

Mechanical force induces HGF proliferation. As presented in Fig. 2A, HGFs had a long, fusiform shape, with radial and swirling growth. In addition, HGFs were positive for vimentin staining (Fig. 2B) and negative for keratin staining (Fig. 2C). Based on the sample origin combined with the mesodermal nature of the cells (rather than epithelial), the cells were considered to be HGFs. Histological sections revealed 2-3 layers of HGFs overlying the surface of the 3D scaffold. Throughout the scaffold, the cells exhibited an elongated shape and were arranged in multiple layers (Fig. 2D). In addition, microfilaments, stained in red, were arranged along the longitudinal axis of the HGFs, as detected by F-actin staining (Fig. 2E).

Forces of 5, 15, 25 and $35 \mathrm{~g} / \mathrm{cm}^{2}$ were applied in the present study. Compared with in the control group (no mechanical force), HGF proliferation increased under the action of 5 and $15 \mathrm{~g} / \mathrm{cm}^{2}$ for $24 \mathrm{~h}$, and cell proliferation activity reached its peak in response to $25 \mathrm{~g} / \mathrm{cm}^{2}$ (Fig. 3A). At $35 \mathrm{~g} / \mathrm{cm}^{2}$, HGF proliferation was inhibited and cell death increased, as measured by flow cytometry (Fig. 3A).

When applying $25 \mathrm{~g} / \mathrm{cm}^{2}$, no significant difference in cell proliferation was observed after $6 \mathrm{~h}$ of stimulation, whereas cell proliferation was significantly increased after 24 (peak) and $48 \mathrm{~h}$ ( $\mathrm{P}<0.05$; Fig. 3B). However, with the gradual increase of application time, the number of cells gradually decreased, and cell proliferation was inhibited after $72 \mathrm{~h}$ (Fig. 3B).

COL-1 and MMP-1 mRNA and protein expression is altered in response to mechanical force in HGFs. Under $25 \mathrm{~g} / \mathrm{cm}^{2}$, the mRNA and protein expression levels of COL-1 were upregulated compared with in the control group; the highest expression was detected at $24 \mathrm{~h}$, whereas the expression level was decreased at 48 and $72 \mathrm{~h}$ (Fig. 4A and B). Conversely, the mRNA and protein expression levels of MMP-1 were lowest at $24 \mathrm{~h}$, and were consequently increased with time, although they remained lower than the control group (Fig. 4C and D).

Mechanical force increases TGF- $\beta 1$ expression in HGFs. The results of RT-qPCR analysis demonstrated that the mRNA expression levels of TGF- $\beta 1$ were upregulated in response to mechanical force; the highest expression was detected at $24 \mathrm{~h}$, 

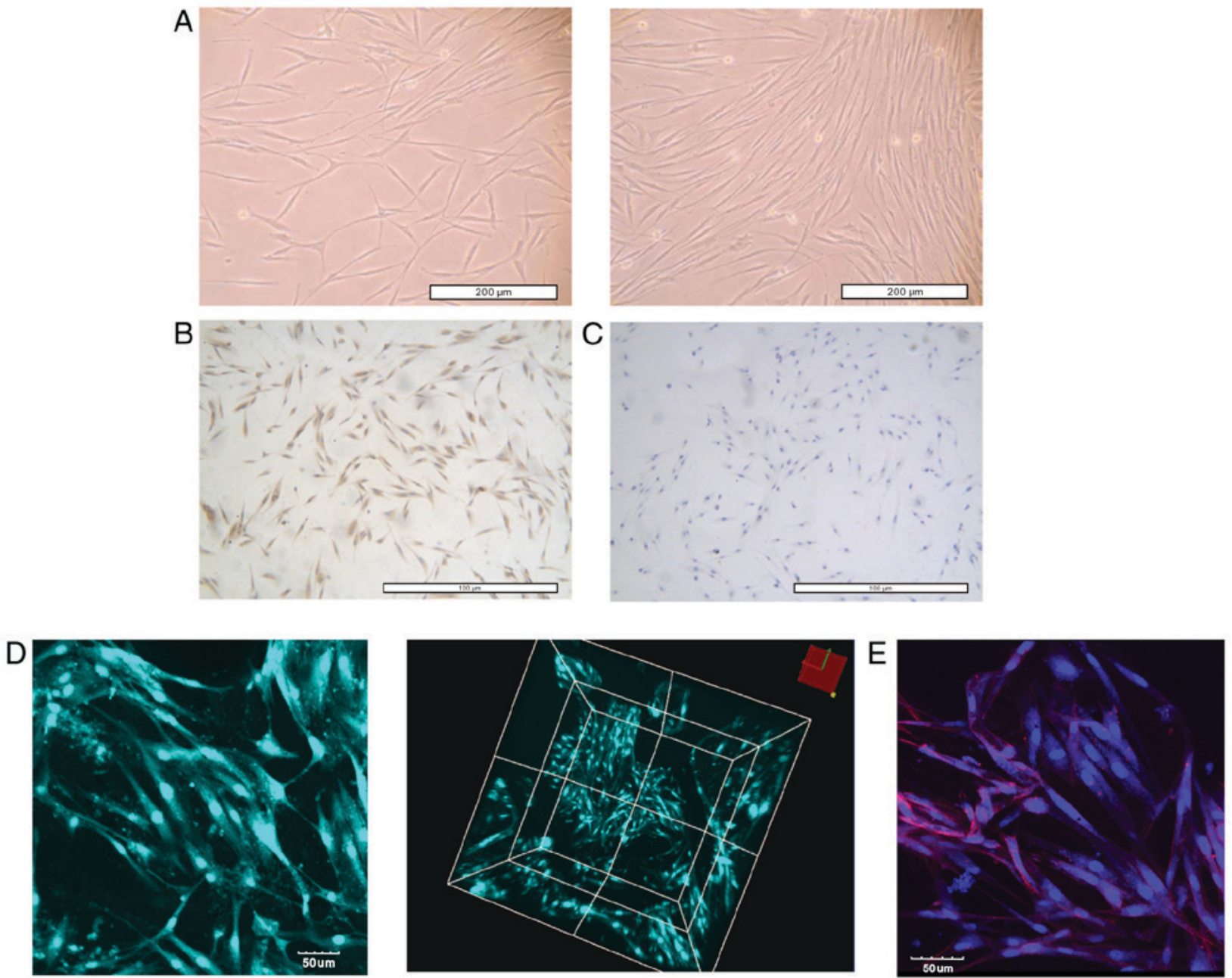

Figure 2. Identification and morphology of HGFs on the 3D PLGA culture model. (A) Representative micrographs of HGFs under an optical microscope. Immunohistochemical staining of (B) vimentin and (C) cytokeratin. (D) Growth mode of HGFs cultured on the 3D PLGA scaffold. (E) F-actin in HGFs was stained with tetramethylrhodamine-phalloidin. HGFs, human gingival fibroblasts; PLGA, poly(lactide-co-glycolide).
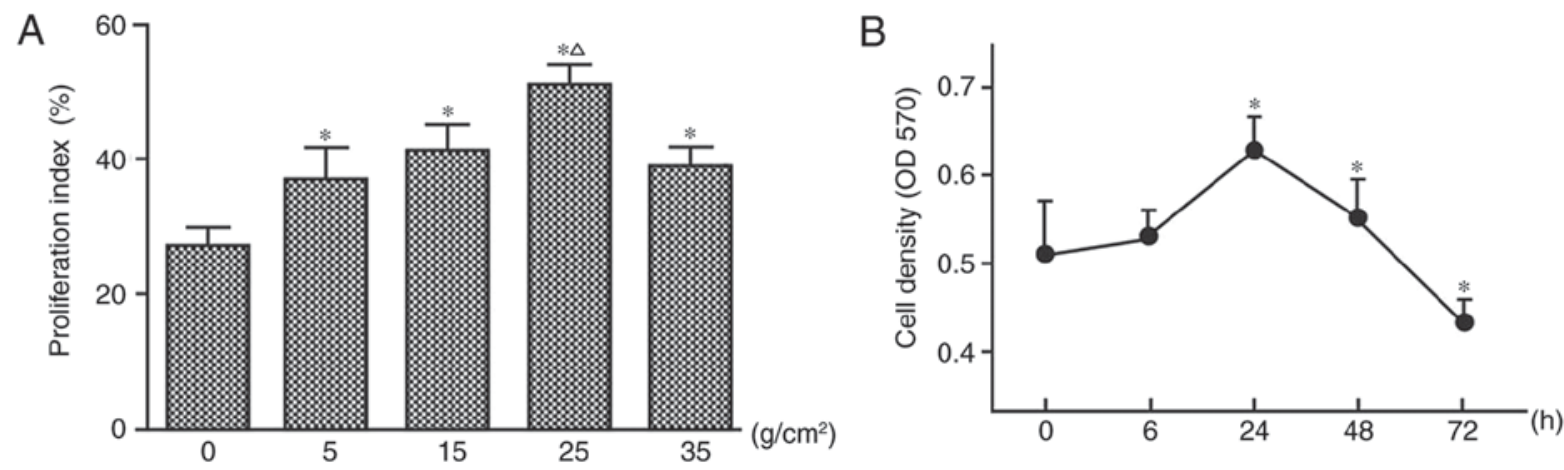

Figure 3. Mechanical force induces the proliferation of HGFs. (A) Proliferation index was calculated by flow cytometry following the application of four different force magnitudes $\left(0,5,15,25\right.$ and $\left.35 \mathrm{~g} / \mathrm{cm}^{2}\right)$ for $24 \mathrm{~h}$. (B) HGF proliferation under $25 \mathrm{~g} / \mathrm{cm}^{2}$ for $0,6,24,48$ and $72 \mathrm{~h}$, as measured by MTT assay. ${ }^{*} \mathrm{P}<0.05$ vs. the control group; ${ }^{\wedge} \mathrm{P}<0.05$ vs. 5,15 and $35 \mathrm{~g} / \mathrm{cm}^{2}$. One-way analysis of variance followed by Dunnett's post hoc test was used to analyze data. HGFs, human gingival fibroblasts; OD, optical density.

whereas the expression level was decreased at 48 and $72 \mathrm{~h}$ $(\mathrm{P}<0.05 ;$ Fig. 5A). In addition, compared with in the control group, no significant alterations in TGF- $\beta 1$ protein expression were observed at $6 \mathrm{~h}$; however, protein expression was significantly increased after $24 \mathrm{~h}$, and was decreased over time after this point.
TGF- $\beta 1$ inhibitor reverses the effects of mechanical force on cell proliferation, and COL-1 and MMP-1 expression in $H G F s$. To determine whether TGF- $\beta 1$ mediated the effects of mechanical force on HGF proliferation, as well as COL-1 and MMP- 1 expression, cells were treated with the TGF- $\beta 1$ inhibitor SB431542 at $20 \mu \mathrm{M}$. The results indicated that mechanical 
A

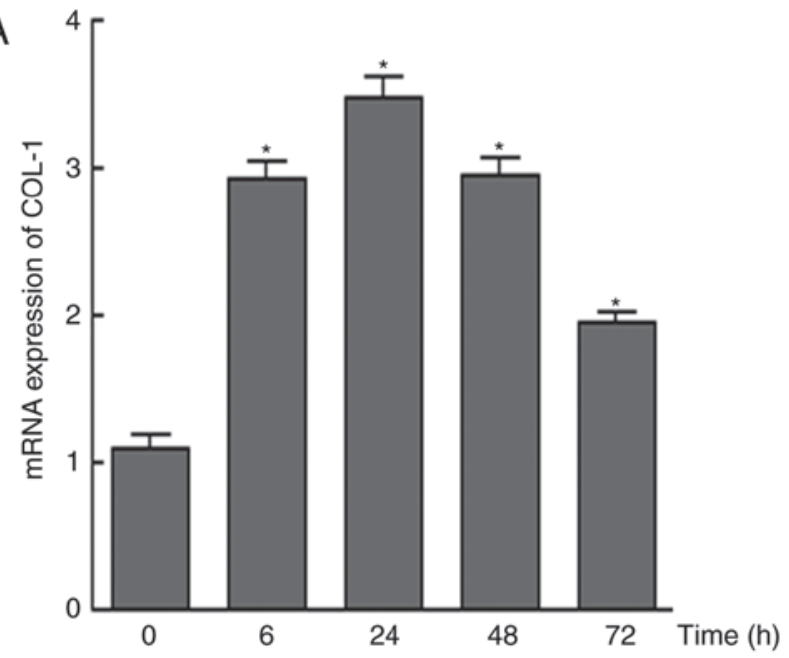

C

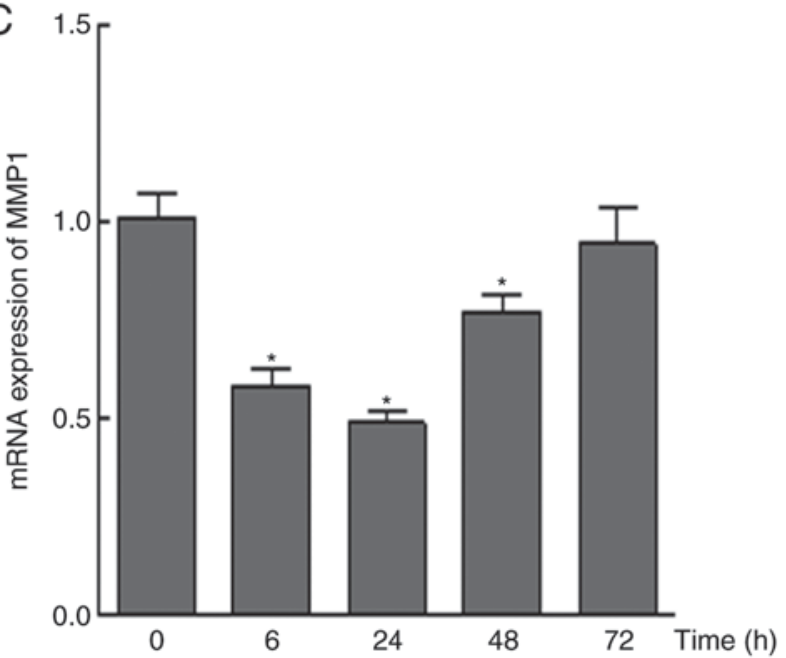

B
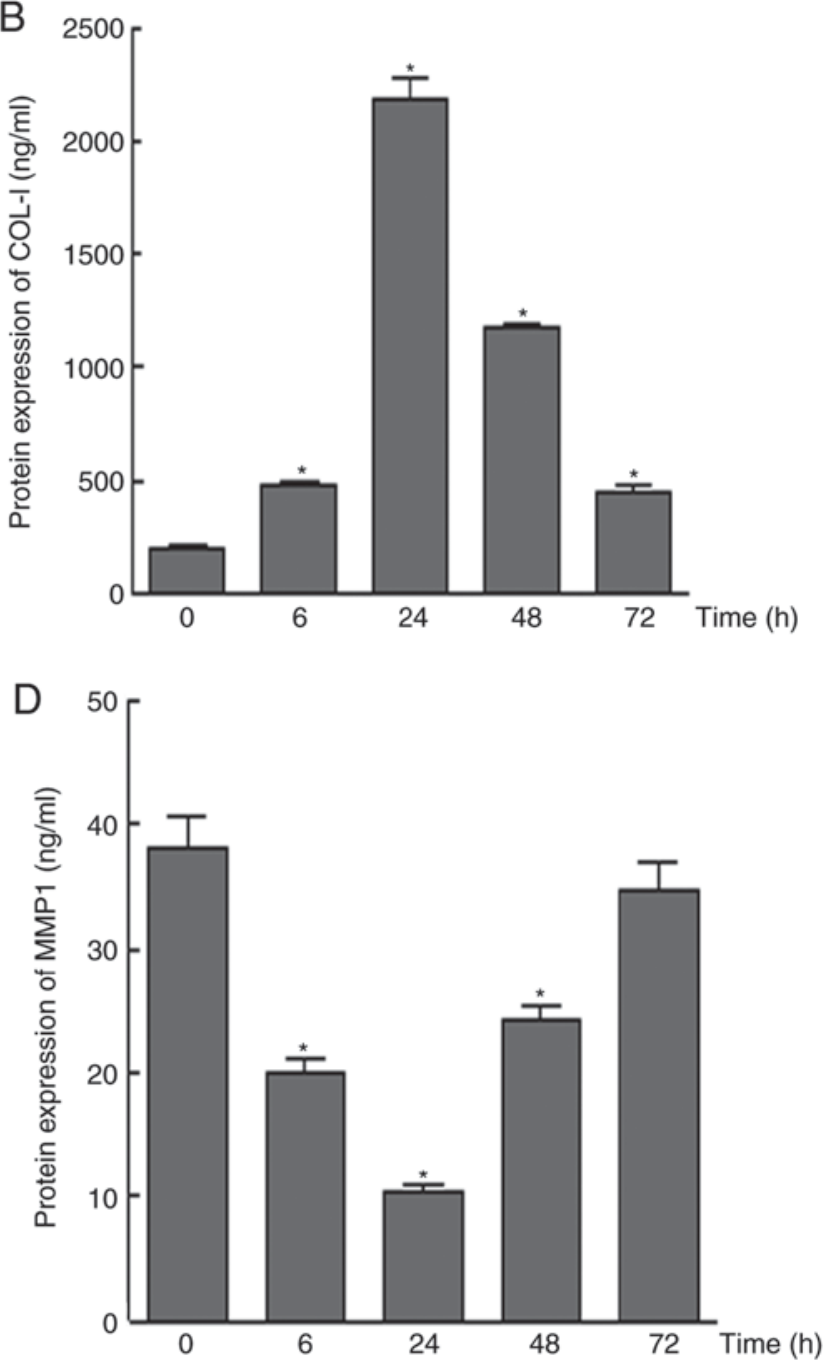

Figure 4. COL-1 and MMP-1 mRNA and protein expression is altered in response to mechanical force in human gingival fibroblasts. mRNA and protein expression of (A and B) COL-1 and (C and D) MMP-1 following the application of mechanical force. ${ }^{*} \mathrm{P}<0.05$ vs. the control group. One-way analysis of variance followed by Dunnett's post hoc test was used to analyze data. COL-1, type I collagen; MMP-1, matrix metallopeptidase.

force-induced upregulation of COL-1 expression and downregulation of MMP-1 expression were reversed in the presence of SB431542 (Fig. 6). These data suggested that TGF- $\beta 1$ may be a key regulator in the of HGF biological function induced by mechanical force. As shown in Fig. 7, presents the effects of the TGF- $\beta 1$ inhibitor SB431542 were also determined on cell proliferation. Compared with in the control group, cells only treated with SB431542 for 24 h did not exhibit a significant decrease in cell proliferation $(\mathrm{P}>0.05)$. However, continuous stimulation with SB431542 for $24 \mathrm{~h}$ significantly decreased mechanical stress-induced cell proliferation compared with in the mechanical stress group $(\mathrm{P}<0.05)$.

\section{Discussion}

The present study strongly indicated that the application of mechanical force on HGFs cultured on 3D PLGA scaffolds led to a significant increase in cell proliferation and in COL-1 gene expression, as well as a decrease in MMP-1 expression. Furthermore, these effects were mediated, at least partially, via the TGF- $\beta$ signaling pathway. These findings further elucidated the mechanisms underlying mechanical force-induced HGF proliferation and ECM synthesis, and may aid in the development of targeted therapeutics, in a pre-clinical and clinical setting.

A growing body of evidence has suggested that 3D cell culture systems, in contrast to $2 \mathrm{D}$ culture systems, more accurately represent the microenvironment in which cells reside in tissues (16). Therefore, the behavior of 3D-cultured cells is more reflective of the actual in vivo cellular responses. Kang et al (22) attempted to use collagen gel to establish a $3 \mathrm{D}$ culture model of periodontal ligament cells; however, the porosity and pressure resistance, as well as other characteristics of the periodontal ligament are significantly different to those of collagen gel (22). The PLGA used in the present study is a copolymer of polyglycolic acid (PGA) and polylactic acid (PLA), which has the advantages of PGA in terms of cell adhesion, and PLA in terms of mechanical strength $(18,23)$. In addition, it is more consistent with periodontal ligament tissue, regarding its physical characteristics. Furthermore, hypoxia must be considered. In previous studies, four-point bending and Flexcell loading models were used to expose the cells to 

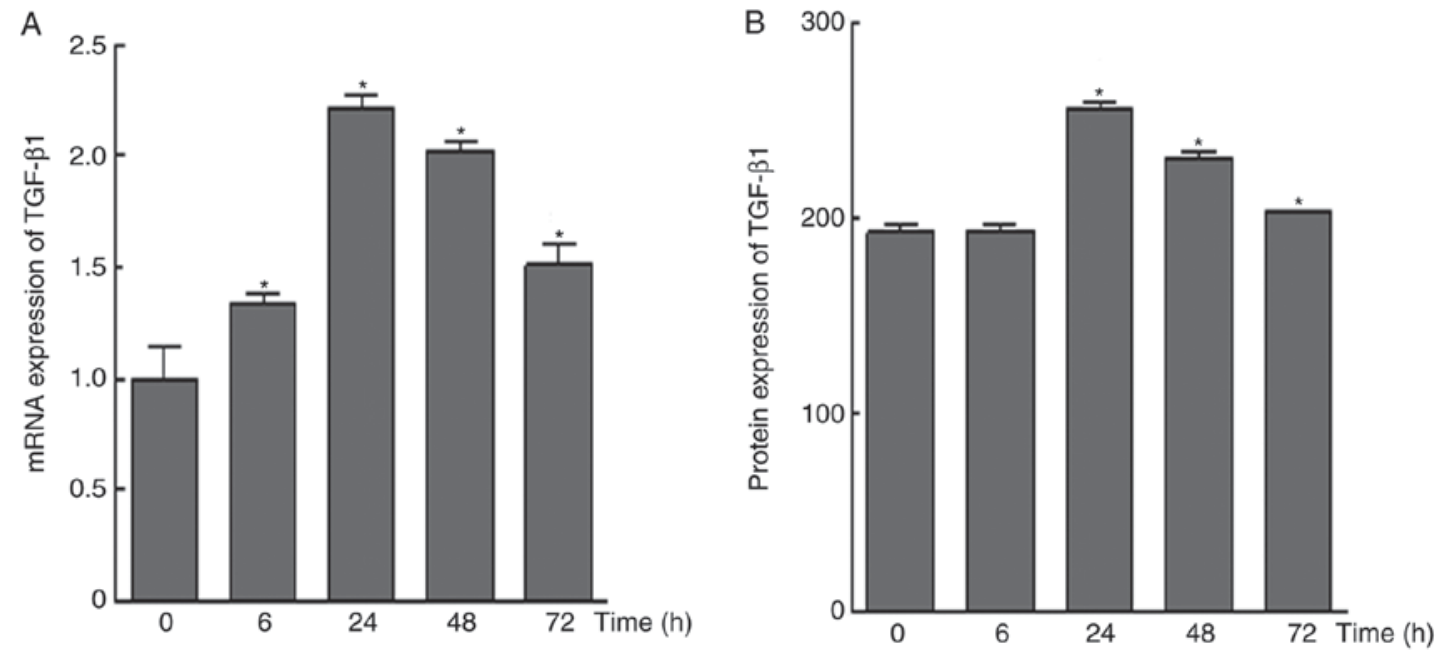

Figure 5. Mechanical force results in elevated TGF- $\beta 1$ expression in human gingival fibroblasts. Expression levels of TGF- $\beta 1$ (A) mRNA and (B) protein following the application of $25 \mathrm{~g} / \mathrm{cm}^{2}$ mechanical force for $0,6,24,48$ and $72 \mathrm{~h}$. "P<0.05 vs. the control group. One-way analysis of variance followed by Dunnett's post hoc test was used to analyze data. TGF- $\beta 1$, transforming growth factor- $\beta 1$.

A

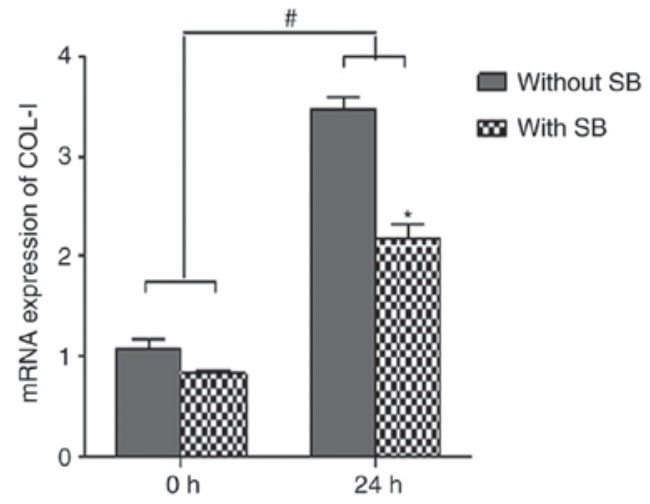

C

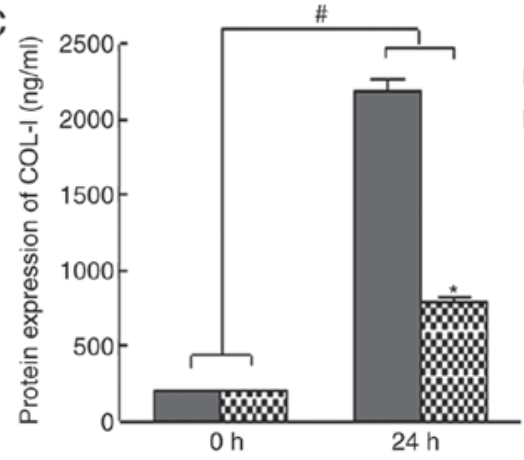

B

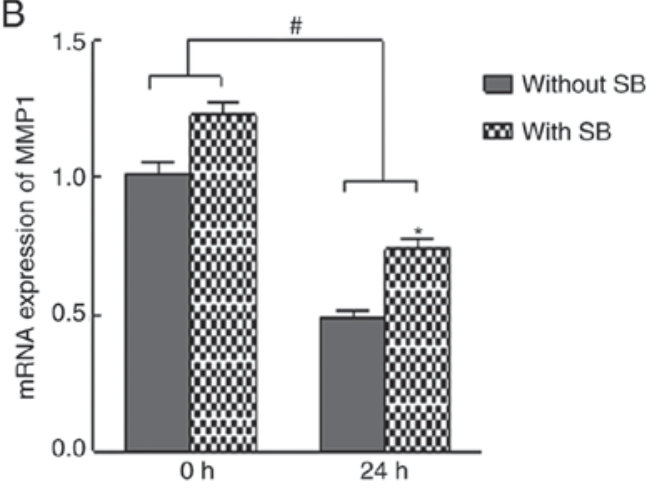

D

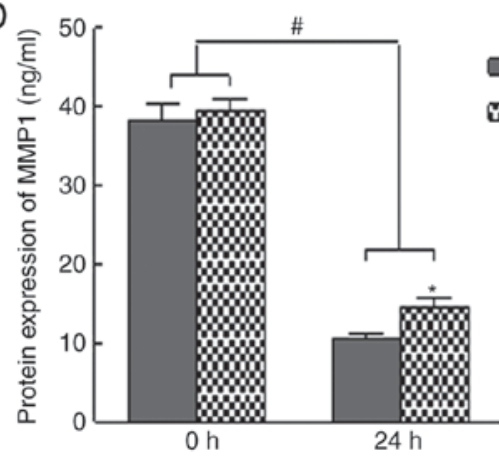

Figure 6. Inhibition of TGF- $\beta$ prevents the effects of mechanical force on COL- 1 and MMP-1 expression in human gingival fibroblasts. Effects of the TGF- $\beta 1$ inhibitor SB (20 $\mu \mathrm{M})$ on mechanical force-induced (A) COL-1 and (B) MMP-1 mRNA expression. Effects of SB on (C) COL-1 and (D) MMP-1 protein expression. $\mathrm{P}<0.05$ vs. cells without SB431542; ${ }^{\prime} \mathrm{P}<0.05$ vs. the corresponding control group at 0 h. One-way analysis of variance followed by Dunnett's post hoc test was used to analyze data. COL-1, type I collagen; MMP-1, matrix metallopeptidase; SB, TGF- $\beta 1$ inhibitor SB431542; TGF- $\beta 1$, transforming growth factor- $\beta 1$.

aerobic conditions (24). When applying mechanical forces to the teeth, due to vascular atresia, the periodontal ligament cells on the pressure side suffer simultaneously from mechanical and hypoxic stimuli, which interact and promote osteoclast formation, facilitating the absorption of alveolar bone on the pressure side. The combination of these stimuli were demonstrated to be beneficial to orthodontic tooth movement $(25,26)$. In the present study, cells in the central part of the complex were under hypoxic and nutrient deprivation conditions due to limited diffusion following the application of mechanical force. Therefore, the PLGA 3D model simultaneously simulated the effects of mechanical force and the hypoxic environment, providing a solid foundation for subsequent experiments.

Mechanical stimulation has an important function in the improvement of orthodontic tooth movement. Kook et al $(27,28)$ demonstrated that periodontal ligament fibroblasts secrete relatively higher levels of tumor necrosis factor- $\alpha$ in the compression side compared with the tension 


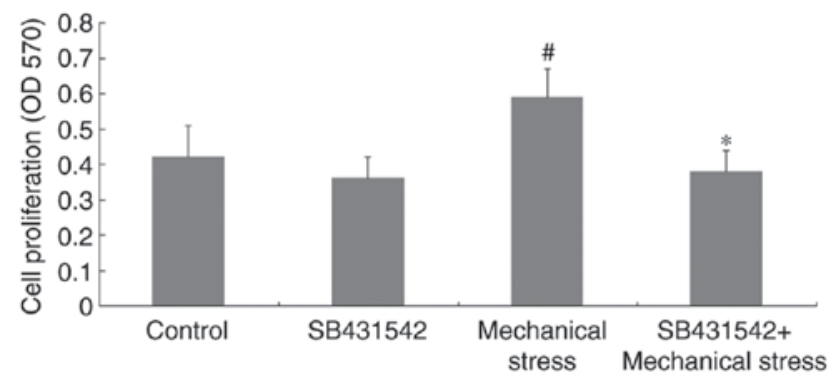

Figure 7. Effects of the TGF- $\beta 1$ inhibitor SB431542 on cell proliferation ${ }^{*} \mathrm{P}<0.05$ vs. the mechanical stress group; ${ }^{\#} \mathrm{P}<0.05$ vs. the control group. Two-way analysis of variance with Bonferroni post hoc test was used to analyze data.

side following application of mechanical stimuli, thereby facilitating bone resorption during orthodontic tooth movement $(27,28)$. Improved simulation of orthodontic treatment in vitro is an important branch of cell biomechanics research. The concept of optimal orthodontic force in orthodontic treatment was first described in 1932 by Schwarz (29). The optimal orthodontic force was calculated by analyzing the capillary pressure at the periodontal ligament on the root surface. Notably, periodontal tissue may undergo ischemia and necrosis under high orthodontic force. In the majority of mammals and humans, the force value is $20-26 \mathrm{~g} / \mathrm{cm}^{2}$; therefore, in the present study, force magnitudes of $5,15,25$ and $35 \mathrm{~g} / \mathrm{cm}^{2}$ were applied. It was revealed that when the force magnitude was 5 and $15 \mathrm{~g} / \mathrm{cm}^{2}$, HGF proliferation was enhanced, and cell proliferation was the highest at $25 \mathrm{~g} / \mathrm{cm}^{2}$. In addition, when the force magnitude reached $35 \mathrm{~g} / \mathrm{cm}^{2}$, HGF proliferation was inhibited. These results were consistent with those of a previous study (30). Thus, $25 \mathrm{~g} / \mathrm{cm}^{2}$ was selected for the subsequent experiments.

Mechanical forces of various magnitudes applied to HGFs affect cell proliferation, function and ECM metabolism through the autocrine or paracrine secretion of various cytokines (31). In the present study, HGF proliferation and COL-1 expression was increased after $6 \mathrm{~h}$ and peaked at $24 \mathrm{~h}$ under $25 \mathrm{~g} / \mathrm{cm}^{2}$. COL-1 expression began to decrease after $48 \mathrm{~h}$, and cell proliferation activity began to decrease after $72 \mathrm{~h}$. In addition, MMP-1 expression was decreased after $6 \mathrm{~h}$ of force application under $25 \mathrm{~g} / \mathrm{cm}^{2}$, and reached a nadir at $24 \mathrm{~h}$. Its expression subsequently increased after $48 \mathrm{~h}$. Previous studies have demonstrated that orthodontic force as an extrinsic mechanical stimulus not only moves the teeth, but also rebuilds equilibrium through evoking a biological cellular response within periodontal tissues (32). The alterations in HGF proliferation by different mechanical forces may have reflected the establishment of a new equilibrium.

TGF- $\beta$ is expressed in several cell types, including HGFs, and is involved in the proliferation and differentiation of these cells $(33,34)$. The functions of TGF- $\beta$ are autocrine or paracrine, since they are involved in the regulation of HGFs during oral inflammation as well as wound healing processes at the site of injury (35). Previous studies have evaluated the effects of TGF- $\beta$ on cell proliferation and collagen metabolism in primary human periodontal ligament cells in vitro. It was revealed that TGF- $\beta$ significantly increases cell proliferation, as well as COL-1 collagen expression (36). Furthermore,
Kimoto et al (37) focused on the effects of intermittent mechanical strain on the cytokine synthesis of HGFs in vitro in a 2D cell culture model, revealing that mechanical stretching induced TGF- $\beta$ secretion. These findings suggest that HGFs synthesize and secrete TGF- $\beta$ as autocrine or paracrine factors that affect bone remodeling and root resorption. The levels of these factors are altered in response to mechanical stress. Consistent with previous studies, the results of the present study determined that TGF- $\beta$ levels were increased $6 \mathrm{~h}$ after force application under $25 \mathrm{~g} / \mathrm{cm}^{2}$, whereas TGF- $\beta$ levels began to decrease after $48 \mathrm{~h}$. The selective TGF- $\beta$ inhibitor SB431642 prevented the effects of mechanical force on HGF proliferation, upregulation of COL-1 expression and downregulation of MMP-1, indicating that TGF- $\beta$ served an important role in gingival tissue remodeling mediated by mechanical force. Nevertheless, the effects of TGF- $\beta$ on HGFs should be further demonstrated using a more rigorous approach that includes genetic knockouts, small interfering RNAs and overexpression vectors. This will be performed in future experiments.

In conclusion, HGFs were cultured on 3D PLGA scaffolds and the results strongly suggested that inhibition or reduction of local TGF- $\beta$ expression decreased HGF proliferation and COL-1 expression, and increased MMP-1 expression. These effects may lead to an increased degradation of collagen fibrils in the ECM and decreased gingival hyperplasia following orthodontic treatments. The modulation of TGF- $\beta$ pathway may contribute to the development of novel therapeutic strategies to promote gingival tissue remodeling.

\section{Acknowledgements}

Not applicable.

\section{Funding}

The present study was supported by grants from the National Natural Science Foundation of China (grant no. 81070860) and the Natural Science Foundation of Guangxi Province (grant no. 2013GXNSFAA019183).

\section{Availability of data and materials}

The datasets used and/or analyzed during the current study are included in this published article.

\section{Authors' contributions}

LN conceived and coordinated the study, designed, performed and analyzed the experiments, and wrote the paper. YZ, NL, SL, YW, ZC, LW, SZ and SM carried out data collection, data analysis and manuscript revisions. All authors reviewed the results and approved the final version of the manuscript.

\section{Ethics approval and consent to participate}

The study was approved by the Hospital Institutional Review Board (approval no. 20150304-22) of Guangxi Medical University (Nanning, China). All donors and their guardians signed an informed consent form. 


\section{Patient consent for publication}

Not applicable.

\section{Competing interests}

The authors declare that they have no competing interests.

\section{References}

1. Dutra EH, Ahmida A, Lima A, Schneider S, Nanda R and Yadav S: The effects of alveolar decortications on orthodontic tooth movement and bone remodelling in rats. Eur J Orthod 40: 423-429, 2018

2. $\mathrm{Pu} \mathrm{H}$ and Hua $\mathrm{Y}$ : Hydrogen sulfide regulates bone remodeling and promotes orthodontic tooth movement. Mol Med Rep 16 : 9415-9422, 2017

3. Jiang N, Guo W, Chen M, Zheng Y, Zhou J, Kim SG, Embree MC, Songhee Song K, Marao HF and Mao JJ: Periodontal ligament and alveolar bone in health and adaptation: Tooth movement. Front Oral Biol 18: 1-8, 2016

4. Dai J, Bi L, Lin J and Qi F: Evaluation of interleukin-10 producing $\mathrm{CD} 19^{+} \mathrm{B}$ cells in human gingival tissue. Arch Oral Biol 84: 112-117, 2017

5. Viecilli RF, Katona TR, Chen J, Hartsfield JK Jr and Roberts WE: Three-dimensional mechanical environment of orthodontic tooth movement and root resorption. Am J Orthod Dentofacial Orthop 133: 791.e11-e26, 2008

6. Kong S, Aoki A, Iwasaki K, Mizutani K, Katagiri S, Suda T, Ichinose S, Ogita M, Pavlic V and Izumi Y: Biological effects of Er:YAG laser irradiation on the proliferation of primary human gingival fibroblasts. J Biophotonics: Nov 2, 2017 (Epub ahead of print). doi: 10.1002/jbio.201700157.

7. Belibasakis GN and Guggenheim B: Induction of prostaglandin $\mathrm{E}(2)$ and interleukin-6 in gingival fibroblasts by oral biofilms. FEMS Immunol Med Microbiol 63: 381-386, 2011.

8. Belibasakis GN, Meier A, Guggenheim B and Bostanci N: The RANKL-OPG system is differentially regulated by supragingival and subgingival biofilm supernatants. Cytokine 55: 98-103, 2011

9. Bostanci N, Meier A, Guggenheim B and Belibasakis GN Regulation of NLRP3 and AIM2 inflammasome gene expression levels in gingival fibroblasts by oral biofilms. Cell Immunol 270 88-93, 2011.

10. Bartold PM and McCulloch CA: Information generation and processing systems that regulate periodontal structure and function. Periodontol 2000 63: 7-13, 2013.

11. Kawahara T, Yamashita M, Ikegami K, Nakamura T, Yanagita M, Yamada S, Kitamura M and Murakami S: TGF-Beta negatively regulates the BMP2-dependent early commitment of periodontal ligament cells into hard tissue forming cells. PLoS One 10 e0125590, 2015.

12. Aukkarasongsup P, Haruyama N, Matsumoto T, Shiga M and Moriyama K: Periostin inhibits hypoxia-induced apoptosis in human periodontal ligament cells via TGF-beta signaling. Biochem Biophys Res Commun 441: 126-132, 2013

13. Xu H, He Y, Feng JQ, Shu R, Liu Z, Li J, Wang Y, Xu Y, Zeng H, $\mathrm{Xu} \mathrm{X}$, et al: Wnt $3 \alpha$ and transforming growth factor- $\beta$ induce myofibroblast differentiation from periodontal ligament cells via different pathways. Exp Cell Res 353: 55-62, 2017

14. Guo F, Carter DE and Leask A: Mechanical tension increases CCN2/CTGF expression and proliferation in gingival fibroblasts via a TGF $\beta$-dependent mechanism. PLoS One 6: e19756, 2011.

15. Jeon YM, Kook SH, Son YO, Kim EM, Park SS, Kim JG and Lee JC: Role of MAPK in mechanical force-induced up-regulation of type I collagen and osteopontin in human gingival fibroblasts. Mol Cell Biochem 320: 45-52, 2009.

16. Ravi M, Paramesh V, Kaviya SR, Anuradha E and Solomon FD 3D cell culture systems: Advantages and applications. J Cell Physiol 230: 16-26, 2015.

17. Sachar A, Strom TA, San Miguel S, Serrano MJ, Svoboda KK and Liu X: Cell-matrix and cell-cell interactions of human gingival fibroblasts on three-dimensional nanofibrous gelatin scaffolds. J Tissue Eng Regen Med 8: 862-873, 2014.

18. Wei G, Jin Q, Giannobile WV and Ma PX: Nano-fibrous scaffold for controlled delivery of recombinant human PDGF-BB. J Control Release 112: 103-110, 2006.
19. Harrington H, Rose FR, Aylott JW and Ghaemmaghami AM Self-reporting scaffolds for 3-dimensional cell culture. J Vis Exp: e50608, 2013.

20. Thadavirul N, Pavasant P and Supaphol P: Improvement of dual-leached polycaprolactone porous scaffolds by incorporating with hydroxyapatite for bone tissue regeneration. J Biomater Sci Polym Ed 25: 1986-2008, 2014.

21. Livak KJ and Schmittgen TD: Analysis of relative gene expression data using real-time quantitative PCR and the 2(-Delta Delta C(T)) method. Methods 25: 402-408, 2001.

22. Kang KL, Lee SW, Ahn YS, Kim SH and Kang YG: Bioinformatic analysis of responsive genes in two-dimension and three-dimension cultured human periodontal ligament cells subjected to compressive stress. J Periodontal Res 48: 87-97, 2013.

23. Ramos T, Ahmed M, Wieringa P and Moroni L: Schwann cells promote endothelial cell migration. Cell Adh Migr 9: 441-451, 2015.

24. Yang L, Yang Y, Wang S, Li Y and Zhao Z: In vitro mechanical loading models for periodontal ligament cells: From two-dimensional to three-dimensional models. Arch Oral Biol 60: 416-424, 2015.

25. Ugolini GS, Pavesi A, Rasponi M, Fiore GB, Kamm R and Soncini M: Human cardiac fibroblasts adaptive responses to controlled combined mechanical strain and oxygen changes in vitro. Elife 6: pii: e22847, 2017.

26. Riddle RC, Leslie JM, Gross TS and Clemens TL: Hypoxiainducible factor-1alpha protein negatively regulates load-induced bone formation. J Biol Chem 286: 44449-44456, 2011.

27. Kook SH, Jang YS and Lee JC: Human periodontal ligament fibroblasts stimulate osteoclastogenesis in response to compression force through TNF- $\alpha$-mediated activation of $\mathrm{CD}^{+}{ }^{+} \mathrm{T}$ cells J Cell Biochem 112: 2891-2901, 2011.

28. Kook SH, Son YO, Hwang JM, Kim EM, Lee CB, Jeon YM, Kim JG and Lee JC: Mechanical force inhibits osteoclastogenic potential of human periodontal ligament fibroblasts through OPG production and ERK-mediated signaling. J Cell Biochem 106: 1010-1019, 2009

29. Schwarz A: Tissue changes incident to orthodontic tooth movement. Int J Orthodontics 18: 331-352, 1932.

30. Li M, Yi J, Yang Y, Zheng W, Li Y and Zhao Z: Investigation of optimal orthodontic force at the cellular level through three-dimensionally cultured periodontal ligament cells. Eur J Orthod 38: 366-372, 2016.

31. Wang JH and Thampatty BP: An introductory review of cell mechanobiology. Biomech Model Mechanobiol 5: 1-16, 2006

32. Krishnan V and Davidovitch Z: Cellular, molecular, and tissue-level reactions to orthodontic force. Am J Orthod Dentofacial Orthop 129: 469.e1-e32, 2006.

33. Cotrim P, Martelli-Junior H, Graner E, Sauk JJ and Coletta RD: Cyclosporin A induces proliferation in human gingival fibroblasts via induction of transforming growth factor-beta1. J Periodontol 74: 1625-1633, 2003.

34. Komatsu Y, Ibi M, Chosa N, Kyakumoto S, Kamo M, Shibata T, Sugiyama Y and Ishisaki A: Zoledronic acid suppresses transforming growth factor- $\beta$-induced fibrogenesis by human gingival fibroblasts. Int J Mol Med 38: 139-147, 2016.

35. Komatsu Y, Ibi M, Chosa N, Kyakumoto S, Kamo M, Shibata T, Sugiyama Y and Ishisaki A: Zoledronic acid suppresses transforming growth factor- $\beta$-induced fibrogenesis by human gingival fibroblasts. Int J Mol Med 38: 139-147, 2016.

36. Watanabe T, Yasue A and Tanaka E: Hypoxia-inducible factor- $1 \alpha$ is required for transforming growth factor- $\beta 1$-induced type I collagen, periostin and $\alpha$-smooth muscle actin expression in human periodontal ligament cells. Arch Oral Biol 59: 595-600, 2014.

37. Kimoto S, Matsuzawa M, Matsubara S, Komatsu T, Uchimura N, Kawase T and Saito S: Cytokine secretion of periodontal ligament fibroblasts derived from human deciduous teeth: Effect of mechanical stress on the secretion of transforming growth factor-beta 1 and macrophage colony stimulating factor. J Periodontal Res 34: 235-243, 1999

This work is licensed under a Creative Commons Attribution-NonCommercial-NoDerivatives 4.0 International (CC BY-NC-ND 4.0) License. 